Research Article

\title{
Synthesis of activated carbons derived from avocado shells as cathode materials for lithium-sulfur batteries
}

\author{
Wissam Fawaz ${ }^{1} \cdot$ Negar Mosavati $^{1} \cdot$ Ehab Abdelhamid ${ }^{2} \cdot$ K. Y. Simon $\mathbf{~ N g}^{1}$ (I)
}

(c) Springer Nature Switzerland AG 2019

\begin{abstract}
Novel mesoporous carbon cathode material for Lithium-Sulfur battery were successfully synthesized from the shells of the avocado fruit. The crystalline structure of the formed carbon was characterized via X-Ray diffraction whilst Scanning Electron Microscopy was used to observe the morphology. The electronic conductivity was determined as a function of pressure and the $\mathrm{COOH}$ functional group were quantified via a titration. The mesoporous structure of the formed carbon network allows for good sulfur penetration which is translated by decent electrochemical performance both in terms of cycle life and rate capability. Carbons prepared from waste avocado shells and functionalized with $\mathrm{HNO}_{3}$ offer a good performance in terms of capacity retention $(500 \mathrm{mAh} / \mathrm{g}$ of sulfur after $100 \mathrm{cycles})$. This favorable performance may be attributed to the role of functional $\mathrm{COOH}$ groups on the surface of the activated carbon.
\end{abstract}

\section{Graphical abstract}

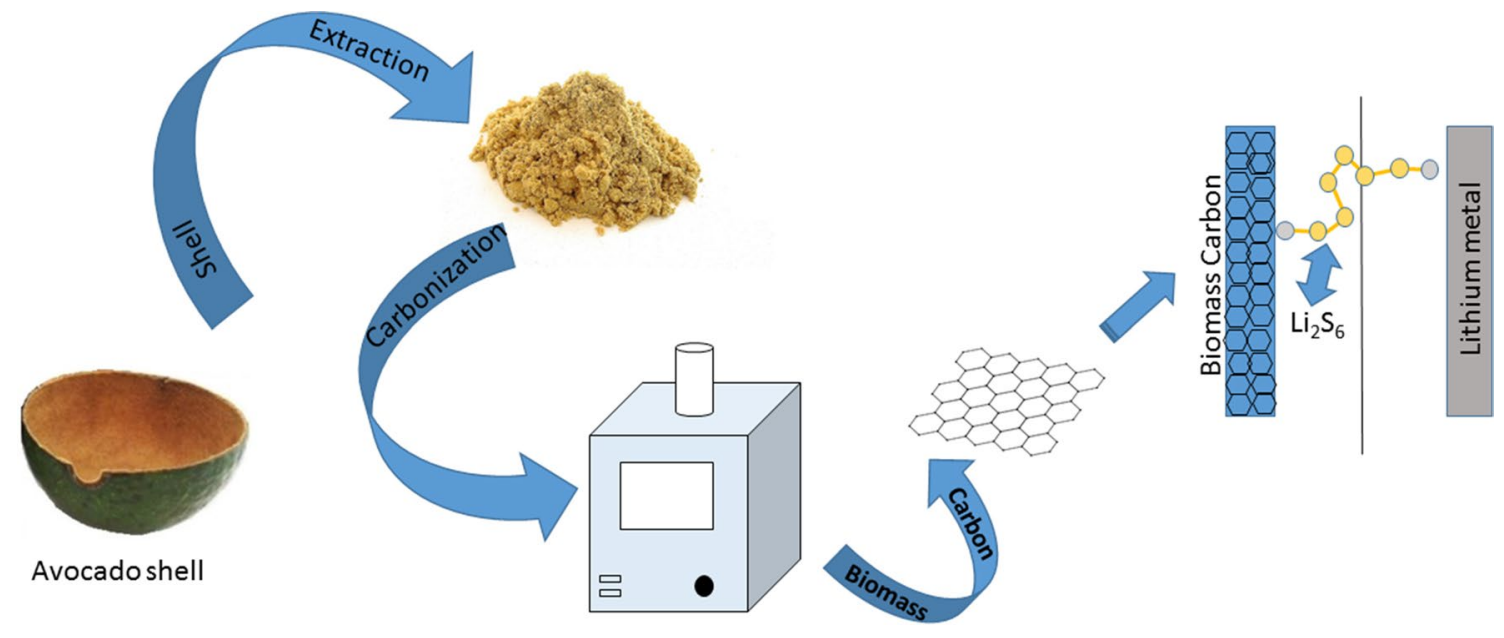

Keywords Biomass · Lithium-Sulfur batteries · Polysulfides · Carbon · Electronic conductivity

Electronic supplementary material The online version of this article (https://doi.org/10.1007/s42452-019-0300-3) contains supplementary material, which is available to authorized users.

$\triangle$ K. Y. Simon Ng, Sng@wayne.edu |'Department of Chemical Engineering and Materials Science, Wayne State University, Detroit, MI 48202, USA. ${ }^{2}$ Department of Physics, Wayne State University, Detroit, MI 48202, USA.

SN Applied Sciences (2019) 1:289 | https://doi.org/10.1007/s42452-019-0300-3 


\section{Introduction}

Despite the prevalent use of Lithium Ion Batteries (LIB) in most modern electronics and electric vehicles, the technology itself is rapidly nearing its upper limits in terms of energy density [1]. An energy heaped alternative could be Lithium-Sulfur systems ( $\mathrm{Li}-\mathrm{S}$ ) with their theoretical $2500 \mathrm{Wh} \mathrm{kg}^{-1}$ energy tab [2-4]. The allure of the Li-S system stems from the low cost of sulfur, its abundance and nontoxic nature, which in turn relaxes many of the restrictions ebbing the current performance of the traditional Lithium Ion Battery cells [5-7].

In spite of its appeal, there are issues that plague Li-S systems:

(a) Loss of active material during cycling [8]: Upon cycling, some of the polysulfides $\left(\mathrm{Li}_{2} \mathrm{~S}_{8}\right.$ to $\left.\mathrm{Li}_{2} \mathrm{~S}_{4}\right)$ reduced during the discharge cycle are not recovered to their initial state, but rather remain dissolved in the electrolyte. Some diffuse to the lithium electrode, where they are further reduced via parasitic reactions to even lower order polysulfides such as $\mathrm{Li}_{2} \mathrm{~S}_{2}$ and $\mathrm{Li}_{2} \mathrm{~S}$ which are insoluble. This continuous loss of active material leads to lower discharge capacity and poor cycle life.

(b) Once some of the soluble polysulfides diffuse to the lithium electrode and undergo the aforementioned reduction reactions, the parasitic polysulfides, now reduced, would travel back to the sulfur side during a phenomenon known as shuttle. These soluble lithium sulfides would ultimately hinder the lithium ion migration and reduce the conductivity of the electrode [9]. The deposition of layers of the dissolved polysulfides on the negative electrode increases surface impedance and subsequently, these insulating species decrease the columbic efficiency of the cell $[10,11]$.

(c) The high resistivity of Sulfur and lithium-sulfides: With a typical resistivity of $2 \times 10^{15} \Omega$.m, sulfur must necessarily be joined to a conductive matrix which would mitigate its lack of conductivity. Carbon is the most widely used material to ameliorate electronic conductivity in most electrochemical systems. These carbons range from simple furnace char [12] all the way to carbon nanofibers $[13,14]$. It has been reported that carbons with either a microporous or a mesoporous [15] structure can minimize the polysulfide redox shuttle effect, and many such structures have been studied in Li-S systems [16]. Another strategy is to form composites from sulfur and a conductive polymer [2]. However these tend to be more arduous and lacking in decent capacity [17].
The generally accepted method to alleviate some of the concerns currently associated with $\mathrm{Li}-\mathrm{S}$ systems is the employment of a carbonaceous matrix to better trap sulfur and assure good conductivity [14].

Conventionally, porous carbons such as superP and graphite have been the carbonaceous support structure of choice for LIB and LI-S systems [18]. Their conductivity could help mitigate the electronically resistive nature of sulfur [19], and their nano-porous structure promotes the physisorption of lithium polysufides and minimizes the shuttle effect [9]. Recently there is a rising interest in biomass derived carbons due to their tunable surfaces [20] and the ease of enriching those surfaces with various functional groups [21]. While carbons of any source may be activated, the intensive and arduous process of tuning surface pores for each specific application drives the cost of the product and greatly taxes the time requirement [22]. In the case of biomass, the decomposition of cellulose and lignin releases trapped gasses and moisture, which gives rise to porosity without the need for chemical reagents [23] or steam activation. One particular method of interest in the tuning of carbon surfaces for battery applications has been the creation of sulfur trapping pores via reflux in a strong acidic bath [24-26]. Moreover, the acid treatment leads to the formation of hydrated surface oxides on the surface of the carbon, which will enhance the adsorption of inorganic compounds [27].

Biowaste products were extensively investigated for numerous applications such as energy storage [3, 14, 28-31], water filtration [32] and the bulk production of activated carbons [33]. The avocado fruit of the Mexican native (Persea Americana) tree is a common waste product of numerous households across the world, which spurred the interest in devising an interesting reuse method for their shells [34].

In this study, avocado shells were first carbonized then treated in nitric acid $\left(\mathrm{HNO}_{3}\right)$ to produce mesoporous carbon with a functionalized surface [35]. The effect of the carboxyl surface functional groups on the electrochemical performance of this activated carbon as cathode support material for liquid polysulfide LI-S systems was investigated. Recently, work done at the US Army research laboratory demonstrated an initial capacity of $500 \mathrm{mAh} / \mathrm{g}$ by using commercial porous carbon as a host matrix for liquid polysulfides [36]. The cell prepared utilizing nitric acid activated avocado shells carbon has an outstanding initial capacity of $1300 \mathrm{mAh} / \mathrm{g}$ with an average decay rate limited to $0.6 \%$ per cycle.

\section{Experimental}

\subsection{Materials}

Potassium carbonate $\left(\mathrm{K}_{2} \mathrm{CO}_{3}\right.$, anhydrous, $\left.>99 \%\right)$ was purchased from Alpha Aesar, Sodium hydroxide 
( $\mathrm{NaOH}$, anhydrous, $>98 \%)$, nitric acid $\left(\mathrm{HNO}_{3}\right.$, ACS Reagent $>90 \%)$ urea $\left(\mathrm{CH}_{4} \mathrm{~N}_{2} \mathrm{O}>99 \%\right)$, elemental sulfur $\mathrm{S}_{8}$ (colloidal 99.98\%), lithium sulfide $\mathrm{Li}_{2} \mathrm{~S}$ (99.98\%), Bis(trifluoromethane)sulfonimide lithium salt $\mathrm{LiN}\left(\mathrm{SO}_{2} \mathrm{CF}_{3}\right)_{2}(>99 \%)$, LiTFSI, triethylene glycol dimethyl ether ( $\mathrm{TG}_{3}$, Reagentplus 99\%) and lithium nitrate $\mathrm{Li}\left(\mathrm{NO}_{3}\right)$ (>99\%) were purchased from Sigma Aldrich and used as received without further alteration.

\subsection{Sample preparation}

Waste avocado shells were washed with deionized water then dried in air. Using an electric grinder, the dried shells were pulverized into a fine powder. The collected avocado shell powder was heated in a nitrogen rich environment to 800 degrees Celsius at a rate of 10 degrees per minute and held for $2 \mathrm{~h}$. The obtained pristine sample will hereafter be denoted as AvS. An AvS sample was refluxed in nitric acid at $100{ }^{\circ} \mathrm{C}$ for $90 \mathrm{~min}$. Post reflux, the sample was washed with copious amounts of $\mathrm{DI}$ water to neutralize its $\mathrm{pH}$, and then dried under vacuum for $12 \mathrm{~h}$. In order to study the effect of surface functional groups of the formed carbon on the electrochemical performance, two more samples were prepared with urea and potassium carbonate by mechanical grinding with the AvS carbon at 1:1 weight ratio. The mixtures were subsequently annealed at 800 degrees for $2 \mathrm{~h}$ in an inert environment at a heating rate of $10^{\circ} \mathrm{C}$ per minutes. These samples were denoted AvS-N, AvS-U and AvS-K respectively and are listed in Table 1. A slurry mixture with an 8:1:1 wt\%(Activated carbon, Super P, PVDF) composition was coated on Aluminum foil via a doctor blade. The coated surfaces were dried under vacuum overnight before circular cathode disks with a diameter of $1 \mathrm{~cm}^{2}$ and an average carbon loading of $5 \mathrm{mg} \mathrm{cm}^{-2}$ were cut. Catholyte solution with $0.2 \mathrm{M} \mathrm{Li}_{2} \mathrm{~S}_{8}, 0.1 \mathrm{M} \mathrm{LiTFSI}$, and $1 \mathrm{M} \mathrm{LiNO}_{3}$ was prepared by stirring stoichiometric amounts of $\mathrm{S}_{8}$ and $\mathrm{Li}_{2} \mathrm{~S}$ into $\mathrm{TG}_{3}$ at $70{ }^{\circ} \mathrm{C}$ for $8 \mathrm{~h}[10,37]$.

A base solution of Lithium Trifluoromethanesuflonate (1 $\mathrm{M} \mathrm{LiCF}_{3} \mathrm{SO}_{3}$ ) and Lithium Nitrate $\left(0.1 \mathrm{M} \mathrm{LiNO}_{3}\right)$ was

Table 1 Mesoporous Carbon Prepared from Avocado Shells

\begin{tabular}{llll}
\hline Sample & Activating agent & Activation method & $\begin{array}{l}\text { Activa- } \\
\text { tion time } \\
\text { (h) }\end{array}$ \\
\hline AvS & None & None & 0 \\
AvS-N & Nitric Acid & Reflux & 2 \\
AvS-K & Potassium Carbonate & Mechanical grinding & 2 \\
AvS-U & Urea & Mechanical grinding & 2 \\
\hline
\end{tabular}

prepared by stirring stochiometric quantities of both agents, to obtain a clear homogenous solution to serve as an electrolyte facilitating the ionic transfer between the lithium electrode and the catholyte.

\subsection{Characterization}

The morphology of the samples was obtained from a field emission scanning electron microscope (SEM, Quanta 400/ INCA/HKL). The specific surface area and pore size distribution of the samples were analyzed using a surface area analyzer (ASAP-2010, Micromeritics, America), and they were calculated by the Brunauer-Emmett-Teller (BET) equation. Electronic conductivity of the samples was measured by a two-probe system to determine the $d c$ resistivity. The setup for electronic conductivity measurement is a variation on the design used by Celzard et al. for moderately compressed powder columns [38]. Powder $X$-ray diffraction (XRD) measurements were conducted on a Rigaku Miniflex diffractometer $(\lambda=1.54 \AA$ ) with $\mathrm{Cu}-\mathrm{Ka}$ radiation operating at $40 \mathrm{kV}$ and $15 \mathrm{~mA}$. Titration was carried out using an OAKTON $\mathrm{pH} 11$ Series $\mathrm{pH} / \mathrm{mV} /{ }^{\circ} \mathrm{C}$ Meter. Graphite procured from the TIMCAL Corporation was used without further activation.

\subsection{Cells assembly and electrochemical measurements}

Electrochemical coin cells were prepared in the following manner: A lithium metal electrode acting as the anode was topped by a separator (celgard 2400 film) soaked in the base electrolyte and pressed against an activated carbon electrode acting as a support for the catholyte. $8 \mu \mathrm{L}$ of catholyte solution was added on the positive electrodes.

Coin cells were cycled 100 times at $0.1 \mathrm{C}$ to examine the cycling stability. An additional cell with graphite support was included as a baseline for comparison. The as prepared activated carbon samples were electrochemically tested via galvanostatic discharge-charge tests on a Maccor Model 4200 Automated Test System between the voltage range of $1.5-3 \mathrm{~V}\left(\mathrm{vs} . \mathrm{Li}^{\prime} \mathrm{Li}^{+}\right)$at room temperature.

Cyclic voltammogram and electrochemical impedance spectroscopy (EIS) measurements of the cells were obtained using a Gamry potentiostat reference 3000 . The voltammetry was performed at a scan rate of $0.1 \mathrm{mV} \mathrm{s}^{-1}$, in the voltage range of 3-1.5 $\mathrm{V}\left(\mathrm{vs}\right.$. $\left.\mathrm{Li}^{\prime} / \mathrm{Li}^{+}\right)$. EIS measurements were recorded between $1 \mathrm{MHz}$ and $0.1 \mathrm{~Hz}$, and $\mathrm{AC}$ amplitude of $10 \mathrm{mV}$ at room temperature. 
Fig. 1 XRD studies of Activated Carbons from Avocado Shells

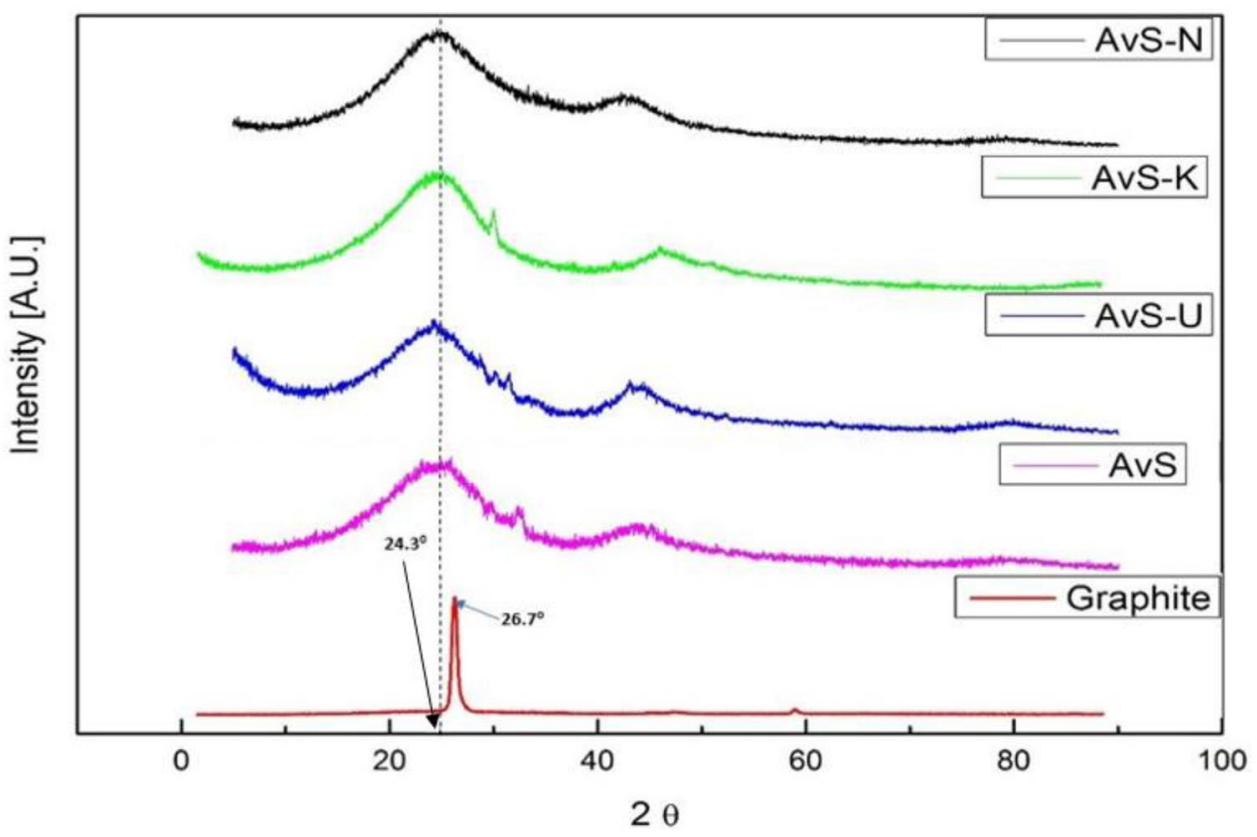

Table 2 Particle sizes

\begin{tabular}{llllr}
\hline Sample & $\begin{array}{l}\text { D-Spacing } \\
(0.22)(\AA)\end{array}$ & Brag angle & FWHM & Size $(\AA)$ \\
\hline AvS & 3.606 & 24.67 & 9.81 & 8.6 \\
AvS-U & 3.490 & 25.50 & 7.09 & 12.0 \\
AvS-K & 3.550 & 25.06 & 4.10 & 20.7 \\
AvS-N & 3.591 & 24.78 & 4.75 & 17.9 \\
Graphite & 3.387 & 26.30 & 0.49 & 175.4 \\
\hline
\end{tabular}

\section{Results and discussion}

The crystal structure of the as prepared carbon was characterized via X-ray diffraction (XRD) (Fig. 1) and shows broadened peaks compared to the diffraction patterns of graphite. The broadening of the peaks at $24.3^{\circ}$ and $43.6^{\circ}$ associated with the (002) and (100) graphite planes reveals a three-dimensional (001) peak and two (hk) dimensional reflections, as well as a lower degree of graphitization. The lower peak at $24.3^{\circ}$ gives a d-spacing of $3.62 \AA$ which is significantly larger than that of perfect graphite (3.34 A) [22]. The FWHM for the AvS sample $\left(\sim 9^{\circ}\right)$, when used in the Scherrer equation (Table 2), reveals a crystallite size of $8.6 \AA$. Given the large disparity from the structure of commercial graphite $(175.4 \AA)$, it's been concluded that carbonized avocado shells gave rise to a poorly crystallized, turbostatic structure where layers are parallel but rotated around the $c$-axis with a low degree of graphitization (-1.9) [39]. The value of the degree of graphitization parameter lies in its relation to the mechanical and thermal properties of the prepared carbon [40], and no impact of its variation was noticed in our electrochemical studies.

The energy dispersive X-ray spectroscopy measurements in (Table 3), suggest that any contaminants present in the pristine carbonized avocado shell have been eliminated and that the carbon to oxygen ratio of the samples is consistent with the affinity to oxygen enjoyed by activated carbons with low degree of crystallinity [41]. The pyrolysis of biomass in an oxygen free environment produces a carbon rich solid remainder that still retains trapped noncondensable constituents such as $\mathrm{CO}$ and $\mathrm{CO}_{2}$ as well as methanol, acetic acid, phenols, hydroxyacetaldehyde,

Table 3 Energy dispersive X-Ray analysis of prepared activated carbons

\begin{tabular}{llllllll}
\hline Sample & Carbon (\%) & Oxygen (\%) & Sodium (\%) & Calcium (\%) & Magnesium (\%) & Potassium (\%) & Si (\%) \\
\hline AvS & 70.37 & 25.67 & 0.06 & 3.26 & 0.40 & 0.18 & 0.06 \\
AvS-U & 89.41 & 10.59 & 0.0 & 0.0 & 0.0 & 0.0 & 0.0 \\
AvS-K & 88.00 & 12.00 & 0.0 & 0.0 & 0.0 & 0.0 & 0.0 \\
AvS-N & 75.22 & 24.78 & 0.0 & 0.0 & 0.0 & 0.0 & 0.0 \\
Graphite & 98.1 & 0.6 & 0.0 & 1.3 & 0.0 & 0.0 \\
\hline
\end{tabular}




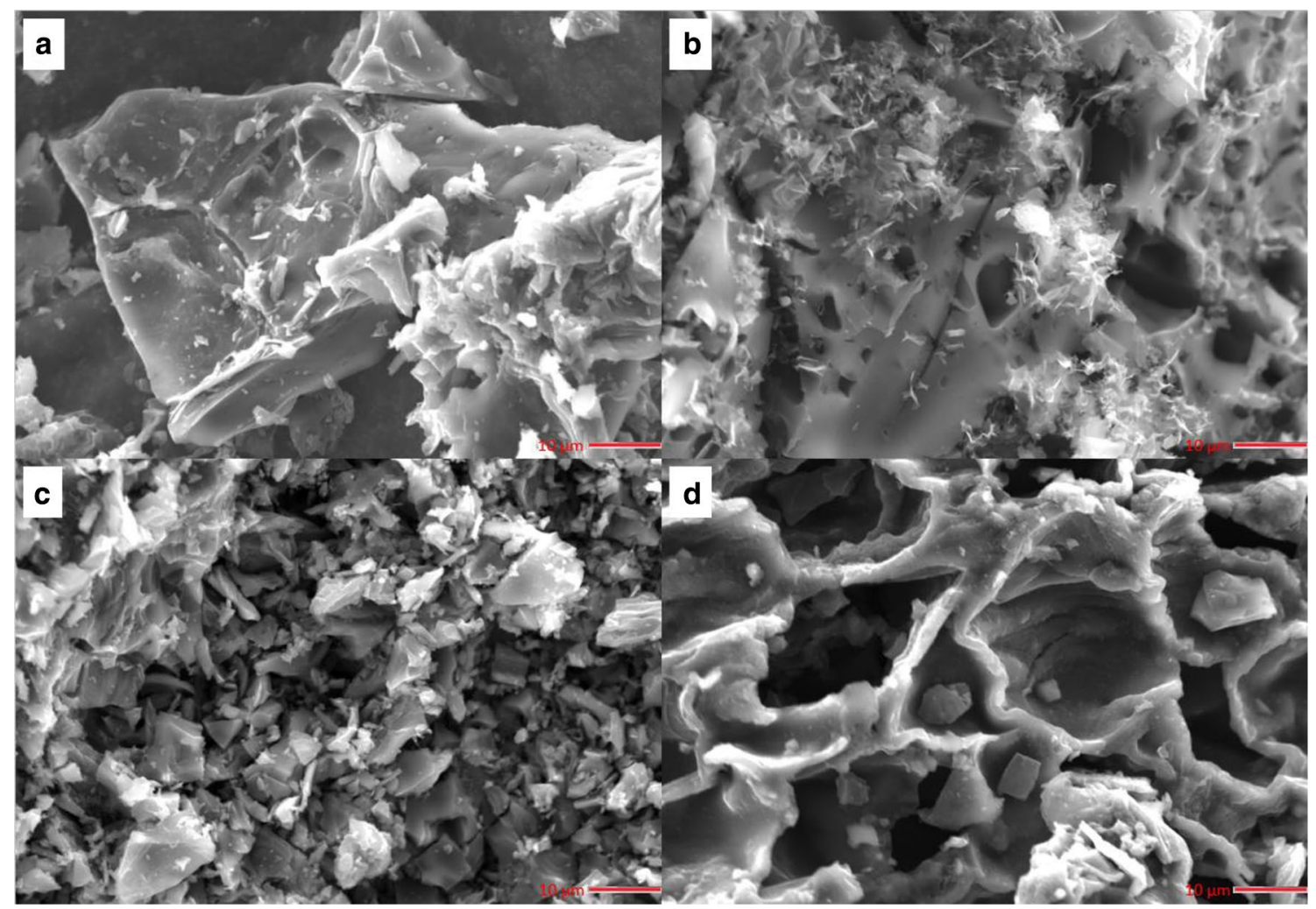

Fig. 2 SEM images of a AvS-U, bAvS-K, c AvS-N, d AvS

Table 4 BET surface area \& porosity of the prepared carbon samples

\begin{tabular}{lccccc}
\hline Sample & Graphite & AvS & AvS-K & AvS-U & AvS-N \\
\hline Surface Area $\left(\mathrm{m}^{2} / \mathrm{g}\right)$ & 20.01 & 1.92 & 1081.39 & 131.93 & 236.63 \\
$\begin{array}{c}\text { Micropore Volume } \\
\left(\mathrm{cm}^{3} \mathrm{~g}^{-1}\right)\end{array}$ & 0.0005 & 0.001 & 0.450 & 0.065 & 0.114 \\
\hline
\end{tabular}

anhydrous monosaccharides and other heavy metals [42]. This accounts for oxygen levels in the AvS sample presented in Table 3.

The XRD peaks of the various activated carbons widen in intensity and are slightly shifted downward when compared with graphite. This shift is a result of the 002 interlayer reflection in amorphous carbon as well as the increase in interlayer spacing of the activated samples as revealed in Table 2 . The line broadening is not well understood and may be attributed to the creation of defective micro graphene layers lacking in planarity, or with an increase in porosity and specific surface area [22]. The SEM images of the prepared activated carbons shows distorted carbonaceous aggregates rather than ordered graphitic layers (Fig. 2) which agrees with the computed value for the degree of graphitization. Upon activation, there appears to be a fusing of those aggregates into discrete, rigid colloidal entities. No increase in porosity is evident from the AvS-U sample (Fig. 2a) where structural changes to the carbon are apparent without distinctive features. The SEM image (Fig. 2b) shows that activation of the carbon with $\mathrm{K}_{2} \mathrm{CO}_{3}$ created micro sized pores which agrees with the porosity shown in Table 4 . The solid honeycomb structure apparent in the AvS sample (Fig. 2d) is lost to a relatively solid mass of continuous carbon structure upon nitric acid activation (Fig. 2c).

AvS-N sample (Fig. 2c) shows a reduced porous structure, and flaky layers which vary in size and alignment. Nitric acid activation does not appear to have improved the porosity of the sample as much as alter the structural arrangement of the carbonaceous layers as reported elsewhere [43].

Topology, surface area and surface functional groups of activated carbons are major influences on resistivity [38, 44-46]: Carboxylic functional groups latch to the diamond like $\mathrm{Sp}^{3}$ carbons which are sparingly available in biomass carbons. This does not affect the electronic conductivity of the activated carbons since that normally only involves $\mathrm{Sp}^{2}$ electrons $[25,38,45]$. Porosity plays an inverse role with conductivity since free moving electrons following the conductive path of their flow, are forced to overcome an increasing number of particle voids and discontinuities in their conductive path [31, 38, 44-49]. This effect is visible in the prepared activated carbon samples as the 


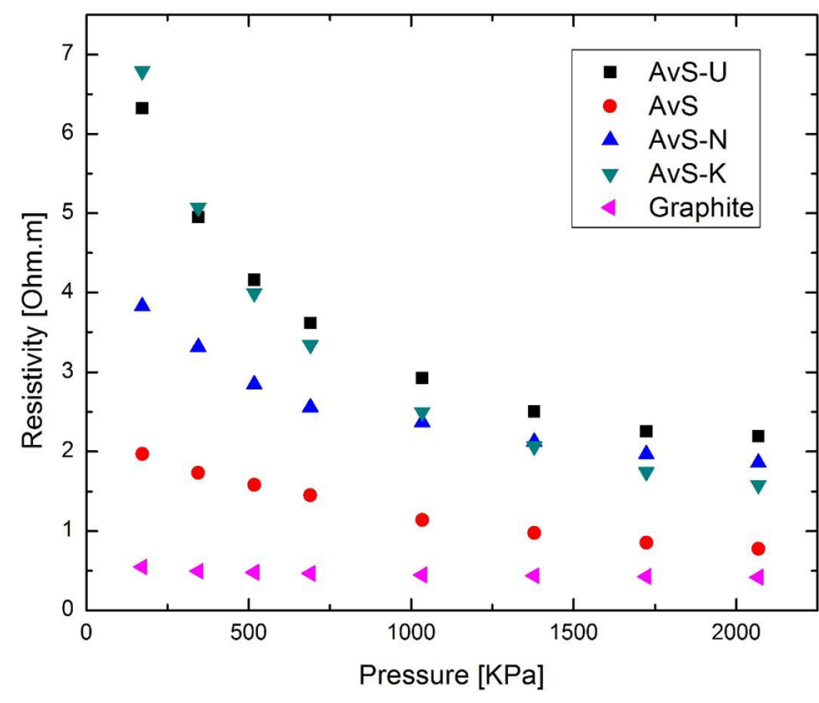

Fig. 3 DC resistivity of prepared activated carbons

conductivity (Fig. 3) increases with pressure, since carbon aggregates get rearranged into a state that increases contact between particles.

Because of the ordered structure of commercial graphite and the lack of functional groups on its surface, little change is observed in its electronic conductivity as the pressure shifts from low to high. For activated carbons however, dc resistivity drops at higher pressure as the conductive crystalline agglomerates become packed close enough to allow hopping of electrons [48].

The presence of carboxylic groups on the surface of the nitric acid functionalized carbon [50] was quantized via a modified Boehm method of titration of a $0.01 \mathrm{M}$ sodium hydroxide solution until the titrant (AvS-N + DI water) reached a neutral $\mathrm{pH}$. The presence of $0.47 \%$ of $\mathrm{COOH}$ per mol of activated carbon was calculated. The creation of these oxygenated groups on the surface of the prepared carbon appear to be presented at the expense of the availability of $\mathrm{Sp}^{2}$ carbon on the surface, which in turn hindered the electronic conductivity of the AvS-N sample (Fig. 3). It has been reported that activation of carbons via other reactant, creates hydroxyl and alkenes groups $\left(\mathrm{K}_{2} \mathrm{CO}_{3}\right)$ [51] or pyridine surface groups (Urea) [52].

Cycling performance of the Li-S cells was assessed by 100 discharge cycles shown in Fig. 4. AvS-N sample shows an initial decay from 2100 to $1300 \mathrm{mAh} / \mathrm{g}$. Capacity continues to fade at an average rate of $4 \%$ per cycle up until the 20th cycle where the rate reduces to an average of $1 \%$ or less per cycle. Graphite suffers an initial capacity fade of $9 \%$ and stabilization to $1.5 \%$ decay rate per cycle occurs around the $32 \mathrm{nd}$ cycle. The other activated carbon samples stabilize after the 25 th cycle and follow similar

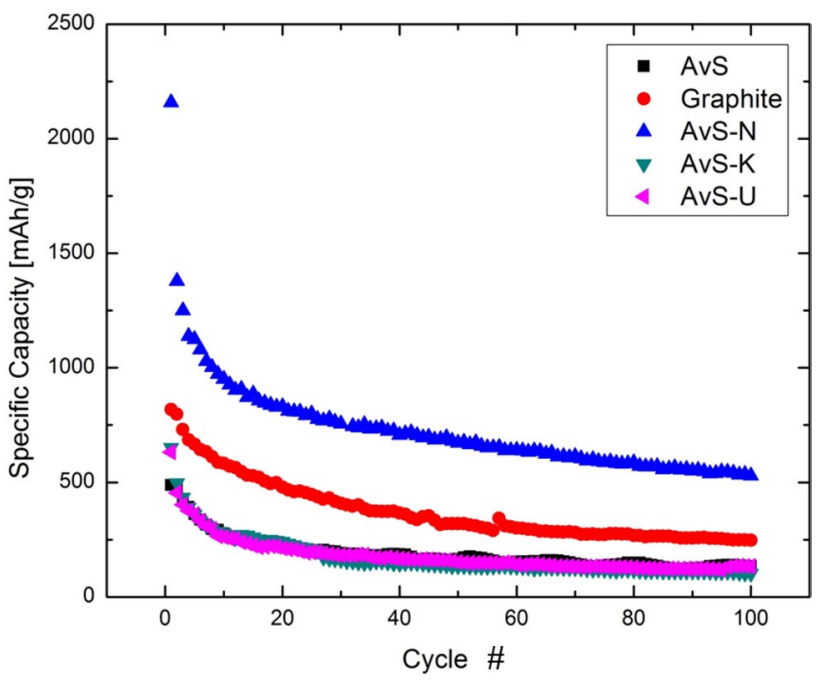

Fig. 4 Specific capacity of activated carbons at $0.1 \mathrm{C}$ rate

capacity drop of around $0.5 \%$ all the way through the 100th cycle.

The AvS-N sample was able to retain $47 \%$ of its initial capacity of $1300 \mathrm{mAh} \mathrm{g}^{-1}$ after 100 cycles to terminate at a capacity of $529.9 \mathrm{mAh} / \mathrm{g}$.

In order to qualitatively investigate the ability of the activated carbon cathode materials to adsorb and trap polysulfide species, each type of carbon was mixed with a $0.02 \mathrm{M}$ dissolved $\mathrm{Li}_{2} \mathrm{~S}_{8}$ solution and stirred for $(8 \mathrm{~h})$. the carbon particles were separated from the dissolved $\mathrm{Li}_{2} \mathrm{~S}_{8}$ particles using a centrifuging technique. The solution containing the AvS-N mixture showed the most adsorption of polysulfide species, qualitatively assessed by the change of solution color. The increased adsorption can be attributed to induced surface charge of the carboxyl groups on the surface of the AvS-N sample, which enhances the binding of sulfur to the $\mathrm{C}-\mathrm{C}$ bond [53]. The solutions containing the other carbon samples showed significantly less discoloration. A photo of the prepared solutions, along with appropriate stoichiometry can be found in the supporting material section.

The transformation of polysulfides into high orders hinges on the ability of the conductive matrix to deliver decent adsorption [54] which in turn leads to an amelioration in the width of the voltage discharge plateau. Galvanostatic charge-discharge profiles of the prepared carbon electrodes and the commercial graphite one at $0.1 \mathrm{C}$ rate and a voltage window between 1.5 and $3.0 \mathrm{~V}$ are shown in Fig. 5. The AvS-N sample shows the widest plateau amongst all samples considered. This is further indication that AvS-N possesses high adsorption capacity for the catholyte. The apparent plateaus corresponding to the conversion of $\mathrm{Li}_{2} \mathrm{~S}_{8}$ to higher and lower order polysulfides respectively species $[55,56]$ are 

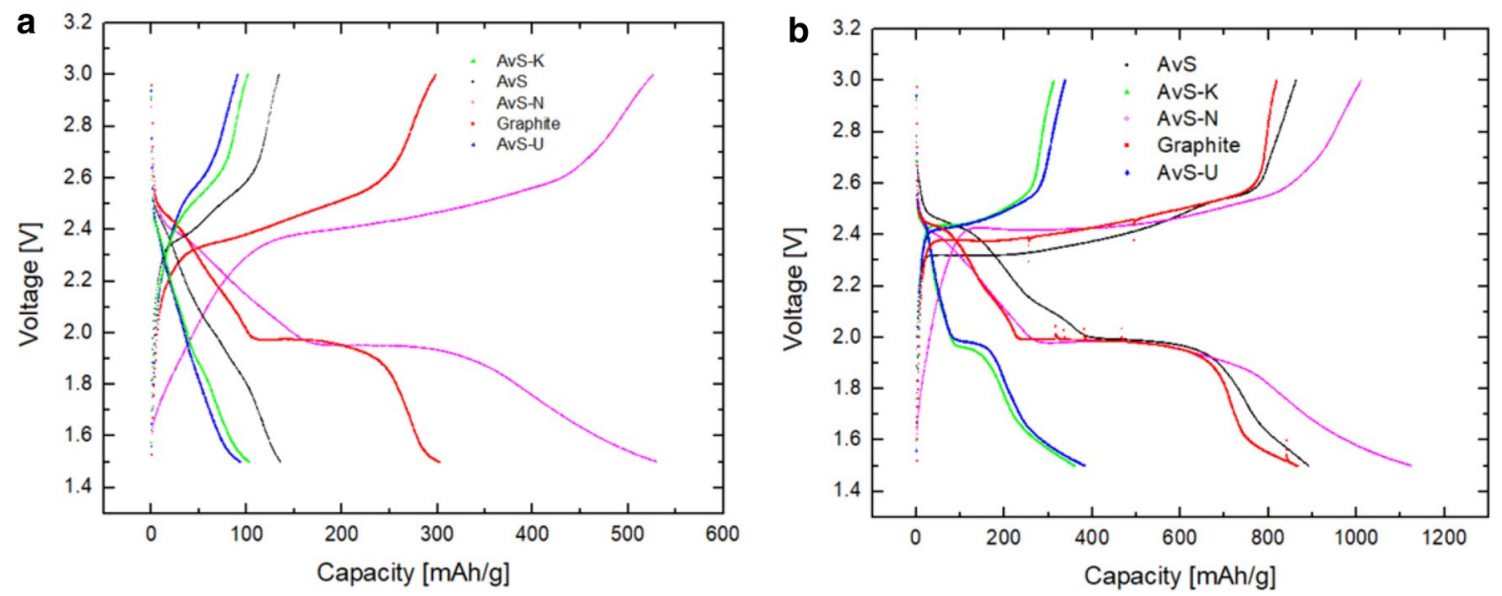

Fig. 5 Galvanostatic charge discharge profile: a 5th cycle, b 100th cycle

Table 5 Capacity retention and rate of decay

\begin{tabular}{lll}
\hline Sample & $\begin{array}{l}\text { Rate of decay at cycle (per } \\
\text { cycle) (\%) }\end{array}$ & $\begin{array}{l}\text { Capacity after } \\
100 \text { cycles } \\
\text { [mAh/g] }\end{array}$ \\
\hline AvS & 1.36 & 135.4 \\
AvS-K & 1.71 & 102.5 \\
AvS-U & 1.42 & 133.6 \\
AvS-N & 0.92 & 529.9 \\
Graphite & 0.72 & 247.6 \\
\hline
\end{tabular}

more pronounced in the AvS-N sample when compared to the other carbons. Discharge profiles for the 100th cycle are presented in Fig. $5 \mathrm{~b}$ to demonstrate that the lower plateau (at $2.1 \mathrm{~V}$ ) is noticeably more extended for AvS-N than the other samples due to AVS-N's better ability to continue the polysulfide conversion. Noticeably, the other activated carbons fail to form a discernible plateau at the 100th cycle as the polysulfide conversion reaction diminished. Avocado shells activated with nitric acid are clearly more apt for the polysulfide conversion and it is reflected in their excellent capacity (Table 5).

Impedance spectroscopy measurements of fresh cells made from prepared carbon materials, having identical sulfur, carbon and catholyte loading, were computed (Fig. 6). Similar measurements were conducted on those cells post cycling and the results are presented in the supplementary material. Table 6 shows the values for the charge transfer resistance (Rct) which is the radius
Fig. 6 Initial Electrochemical Impedance Spectroscopy of all carbonaceous samples employed

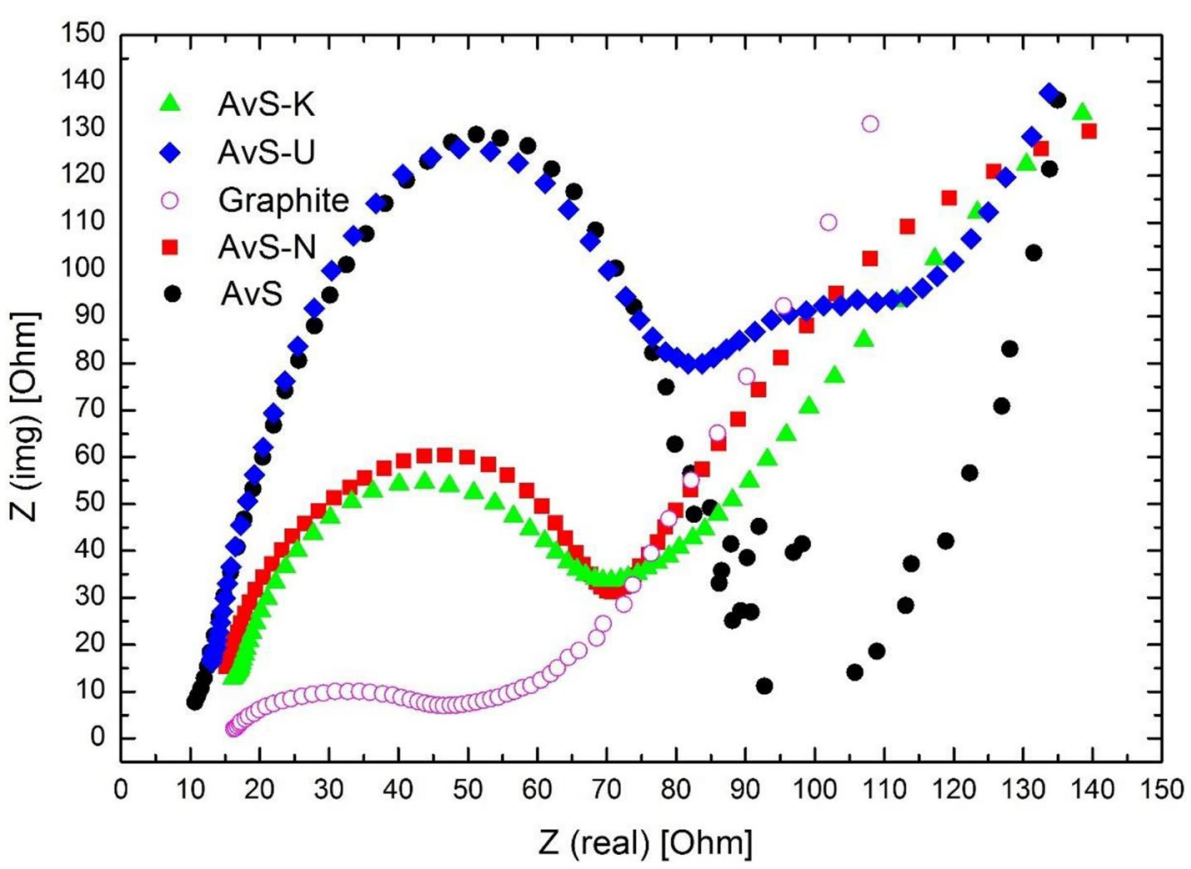


of the semi-circle on the Nyquist plot's high frequency region [57]. After the addition of $10 \%$ conductive superP carbon to the slurry to increase electronic conductivity, it was found that differences in the $R_{\mathrm{ct}}$ value exist between activated carbon samples which may be attributed to their carbonaceous structure and surface functional groups. Among all activated carbons, the AvS-N sample exhibit the least change in $R_{c t}$ values post cycling. This is an indication of better ionic diffusion into the carbonaceous structure than the other samples [58]. The shift towards higher values of Rct after cycling is due to the creation of insoluble species such as $\mathrm{Li}_{2} \mathrm{~S}_{2}$ and LiS which ebb the cyclability of the cell [59]. AvS and AvS-U samples exhibit large charge transfer resistances that hinder their suitability for LiS applications.

Despite AvS-N having a relatively high charge transfer resistance, its better cycle life is likely due to its superior ability to adsorb dissolved polysulfide species in the system. (see supplementary material).

To gain a better understanding of the oxidation and reduction reactions taking place inside these cells, CV curves of the cells prepared with identical loading of sulfur and activated carbons show the first, second and third voltammograms at $0.1 \mathrm{mV} \mathrm{s}^{-1}$ in the range of potential

Table 6 Electrochemical Impedance data: The charge transfer resistance

\begin{tabular}{lll}
\hline Sample & Rct-Init [Ohm] & $\begin{array}{l}\text { \% increase } \\
\text { post cycling } \\
(\%)\end{array}$ \\
\hline AvS & 88.3 & 167.5 \\
AvS-K & 56.8 & 45.23 \\
AvS-U & 74.3 & 54.5 \\
AvS-N & 53.4 & 38.67 \\
\hline
\end{tabular}

between 1.5 and $3.0 \mathrm{~V}$. Two reduction peaks and one oxidation peak are presented at $2.37 \mathrm{~V}, 1.9 \mathrm{~V}$ and $2.5 \mathrm{~V}$ respectively (Fig. 7). The reduction of the liquid $\mathrm{Li}_{2} \mathrm{~S}_{8}$ into intermediary subspecies $\mathrm{Li}_{2} \mathrm{~S}_{\mathrm{x}}(4<\mathrm{x}<6)$ occur during the high voltage cathodic peak while the further reduction into insoluble $\mathrm{Li}_{2} \mathrm{~S}_{2}$ and $\mathrm{Li}_{2} \mathrm{~S}$ happens during the lower voltage cathodic peaks [60]. It is noticeable that the anodic peaks corresponding to the graphite sample lose intensity as the cell cycles going from 43 to $24 \mathrm{~mA}$ which is an indication that the amount of active material capable of being oxidized is diminishing with cycling. The AvS-N sample exhibits a stable behavior across all three CV cycles, with little discernible change in the current response due to its good electrochemical stability, and its ability to adsorb dissolved polysulfide species.

\section{Conclusions}

The effect of surface functionalization on the capacity of the lithium sulfur system was demonstrated through the synthesis of new cathode host material from avocado shells carbon. Cycle life extension and stabilization was achieved through introduction of carboxyl surface groups via nitric acid reflux.

AvS-N carbon material shows good capacity retention and a capacity of 529.85 after 100 cycles which is $72.6 \%$ higher than commercial graphite.

The structure and ameliorated surface of nitric acid functionalized activated carbons are apt conductive host matrix for the improvement of the sulfur utilization and at thwarting the dissolution of polysulfides into the electrolyte.
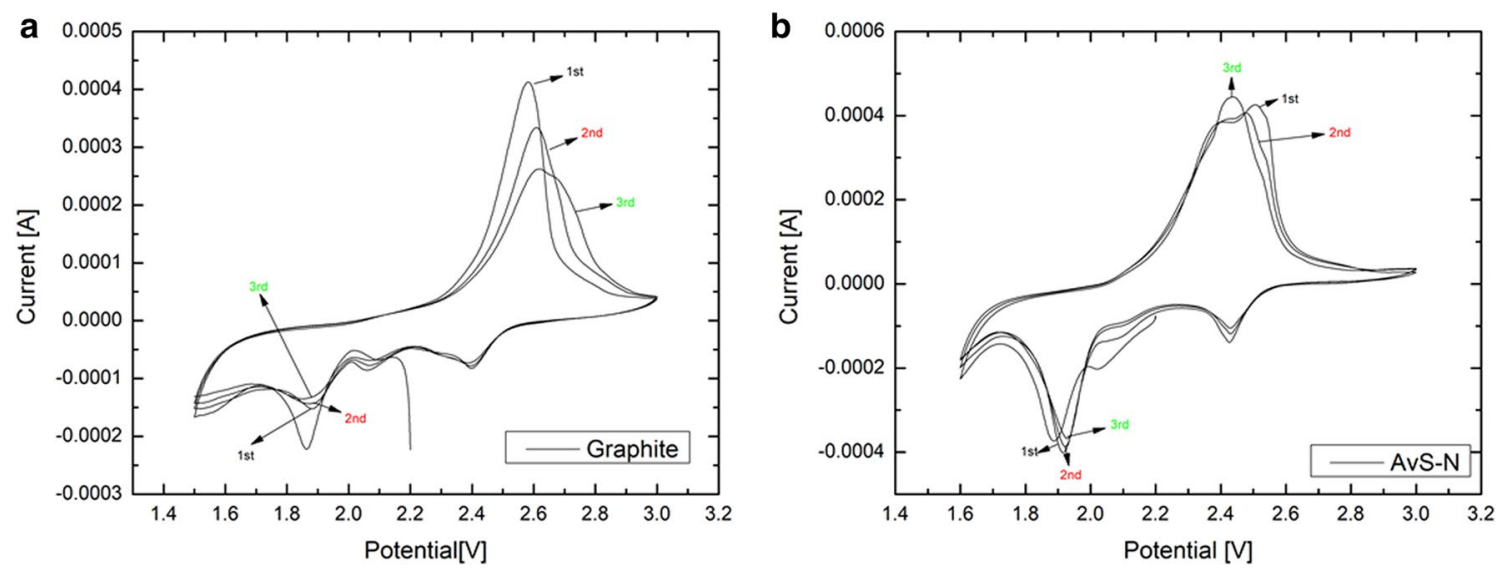

Fig. 7 Cyclic Voltammogram of Li-S cell made with: a graphite anode, b AvS-N anode 


\section{Compliance with ethical standards}

Conflict of interest On behalf of all authors, the corresponding author states that there is no conflict of interest.

\section{References}

1. Balach J, Jaumann T, Klose M, Oswald S, Eckert J, Giebeler L (2015) Mesoporous carbon interlayers with tailored pore volume as polysulfide reservoir for high-energy lithium-sulfur batteries. J Phys Chem C 119(9):4580-4587

2. Nazar LF, Cuisinier M, Pang Q (2014) Lithium-sulfur batteries. MRS Bull 39(5):436-442

3. Park J-W, Kim I, Kim K-W, Nam T-H, Cho K-K, Ahn J-H, Ryu H-S, Ahn H-J (2016) Effect of commercial activated carbons in sulfur cathodes on the electrochemical properties of lithium/sulfur batteries. Mater Res Bull 82:109-114

4. Yamin H, Peled E (1983) Electrochemistry of a nonaqueous lithium/sulfur cell. J Power Sources 9(3):281-287

5. Bruce PG, Freunberger SA, Hardwick LJ, Tarascon J-M (2012) $\mathrm{Li}-\mathrm{O} 2$ and $\mathrm{Li}-\mathrm{S}$ batteries with high energy storage. Nat Mater 11(1):19-29

6. Goodenough JB, Park K-S (2013) The Li-Ion Rechargeable Battery: a Perspective. J Am Chem Soc 135(4):1167-1176

7. Yang Z, Zhang J, Kintner-Meyer MCW, Lu X, Choi D, Lemmon JP, Liu J (2011) Electrochemical Energy Storage for Green Grid. Chem Rev 111(5):3577-3613

8. Manthiram A, Fu Y, Chung S-H, Zu C (2014) Rechargeable lithium-sulfur batteries. Chem Rev 114(23):11751-11787

9. Mikhaylik YV, Akridge JR (2004) Polysulfide shuttle study in the Li/S battery system. J Electrochem Soc 151(11):A1969-A1976

10. Mosavati N, Chitturi VR, Salley SO, Ng KS (2016) Nanostructured titanium nitride as a novel cathode for high performance lithium/dissolved polysulfide batteries. J Power Sources 321:87-93

11. Rauh RD, Abraham KM, Pearson GF, Surprenant JK, Brummer SB (1979) A Lithium/dissolved sulfur battery with an organic electrolyte. J Electrochem Soc 126(4):523-527

12. Jeon BH, Yeon JH, Kim KM, Chung IJ (2002) Preparation and electrochemical properties of lithium-sulfur polymer batteries. J Power Sources 109(1):89-97

13. Rao M, Geng X, Li X, Hu S, Li W (2012) Lithium-sulfur cell with combining carbon nanofibers-sulfur cathode and gel polymer electrolyte. J Power Sources 212:179-185

14. Zhang J, Xiang J, Dong Z, Liu Y, Wu Y, Xu C, Du G (2014) Biomass derived activated carbon with $3 \mathrm{D}$ connected architecture for rechargeable lithium-sulfur batteries. Electrochim Acta 116:146-151

15. Ding B, Yuan C, Shen L, Xu G, Nie P, Zhang X (2013) Encapsulating Sulfur into hierarchically ordered porous carbon as a highperformance cathode for lithium-sulfur batteries. Chem A Eur J 19(3):1013-1019

16. Wu H, Mou J, Zhou L, Zheng Q, Jiang N, Lin D (2016) Cloud caplike, hierarchically porous carbon derived from mushroom as an excellent host cathode for high performance lithium-sulfur batteries. Electrochim Acta 212:1021-1030

17. Yu X (2005) Stable-cycle and high-capacity conductive sulfurcontaining cathode materials for rechargeable lithium batteries. J Power Sources 146(1-2):335-339

18. Ji X, Evers S, Black R, Nazar LF (2011) Stabilizing lithium-sulphur cathodes using polysulphide reservoirs. Nat Commun 2:325

19. Wang JL, Yang J, Xie JY, Xu NX, Li Y (2002) Sulfur - Carbon nanocomposite as cathode for rechargeable lithium battery based on gel electrolyte. Electrochem Commun 4(6):499-502
20. Qu Y, Zhang Z, Zhang X, Ren G, Lai Y, Liu Y, Li J (2015) Highly ordered nitrogen-rich mesoporous carbon derived from biomass waste for high-performance lithium-sulfur batteries. Carbon 84:399-408

21. Demir-Cakan R, Morcrette M, Nouar F, Davoisne C, Devic T, Gonbeau D, Dominko R, Serre C, Férey G, Tarascon J-M (2011) Cathode Composites for Li-S Batteries via the Use of Oxygenated Porous Architectures. J Am Chem Soc 133(40):16154-16160

22. Marsh H, Rodríguez-Reinoso F (2015) Activated carbon. Elsevier, Amsterdam

23. Jagtoyen M, Derbyshire F (1993) Some considerations of the origins of porosity in carbons from chemically activated wood. Carbon 31(7):1185-1192

24. Gómez-Serrano V, Acedo-Ramos M, Acedo-Ramos M, LópezPeinado AJ, Valenzuela-Calahorro C (1997) Mass and surface changes of activated carbon treated with nitric acid. Thermal behavior of the samples. Thermochim Acta 291(1-2):109-115

25. Pittman CU, He GR, Wu B, Gardner SD (1997) Chemical modification of carbon fiber surfaces by nitric acid oxidation followed by reaction with tetraethylenepentamine. Carbon 35(3):317-331

26. Yuan L, Yuan H, Qiu X, Chen L, Zhu W (2009) Improvement of cycle property of sulfur-coated multi-walled carbon nanotubes composite cathode for lithium/sulfur batteries. J Power Sources 189(2):1141-1146

27. Boehm HP (2002) Surface oxides on carbon and their analysis: a critical assessment. Carbon 40(2):145-149

28. Elmouwahidi A, Zapata-Benabithe Z, Carrasco-Marín F, MorenoCastilla C (2012) Activated carbons from $\mathrm{KOH}$-activation of argan (Argania spinosa) seed shells as supercapacitor electrodes. Biores Technol 111:185-190

29. Kim C, Lee J-W, Kim J-H, Yang K-S (2006) Feasibility of bamboobased activated carbons for an electrochemical supercapacitor electrode. Korean J Chem Eng 23(4):592-594

30. Olivares-Marín $M$, Fernández J, Lázaro $M$, Fernández-González $C$, Macías-García A, Gómez-Serrano V, Stoeckli F, Centeno TA (2009) Cherry stones as precursor of activated carbons for supercapacitors. Mater Chem Phys 114(1):323-327

31. Wang P, Wang Q, Zhang G, Jiao H, Deng X, Liu L (2016) Promising activated carbons derived from cabbage leaves and their application in high-performance supercapacitors electrodes. $J$ Solid State Electrochem 20(2):319-325

32. Sun Y, Zhang J-P, Yang G, Li Z-H (2006) Removal of Pollutantswith Activated Carbon Produced from K2CO3 Activation of Lignin From Reed Black Liquors. Chem Biochem Eng Q 20(4):429-435

33. Ruiz Bevia F, Prats Rico D, Marcilla Gomis AF (1984) Activated carbon from almond shells. Chemical activation 1. Activating reagent selection and variables influence. Ind Eng Chem Prod Res Dev 3(2):266-269

34. Georgin J, da Silva Marques B, da Silveira Salla J, Foletto EL, Allasia D, Dotto GL (2018) Removal of Procion Red dye from colored effluents using $\mathrm{H} 2 \mathrm{SO} 4-/ \mathrm{HNO} 3-$ treated avocado shells (Persea americana) as adsorbent. Environ Sci Pollut Res 25(7):6429-6442

35. Biniak S, Pakuła M, Szymański GS, Świątkowski A (1999) Effect of activated carbon surface oxygen- and/or nitrogen-containing groups on adsorption of copper(II) lons from aqueous solution. Langmuir 15(18):6117-6122

36. Zhang SS (2012) Role of LiNO3 in rechargeable lithium/sulfur battery. Electrochim Acta 70:344-348

37. Shin JH, Cairns EJ (2008) Characterization of N-Methyl-NButylpyrrolidinium Bis(trifluoromethanesulfonyl)imide-LiTFSITetra(ethylene glycol) Dimethyl Ether Mixtures as a Li Metal Cell Electrolyte. J Electrochem Soc 155(5):A368-A373

38. Celzard A, Marêché JF, Payot F, Furdin G (2002) Electrical conductivity of carbonaceous powders. Carbon 40(15):2801-2815

39. Kinoshita K (1988) Carbon: electrochemical and physicochemical properties. Wiley, New York 
40. Zou L, Huang B, Huang Y, Huang Q, Wang C (2003) An investigation of heterogeneity of the degree of graphitization in carboncarbon composites. Mater Chem Phys 82(3):654-662

41. Yen BK, Ishihara T (1996) On temperature-dependent tribological regimes and oxidation of carbon-carbon composites up to $1800^{\circ} \mathrm{C}$. Wear 196(1):254-262

42. Pandey, A.; Bhaskar, T.; Stöcker, M.; Sukumaran, R. K., 11.3.1 Charcoal. In Recent Advances in Thermochemical Conversion of Biomass, Elsevier

43. Choma J, Jaroniec M (2001) A model-independent analysis of nitrogen adsorption isotherms on oxidized active carbons. Colloids Surf, A 189(1-3):103-111

44. Liu C-C, Walters AB, Vannice MA (1995) Measurement of electrical properties of a carbon black. Carbon 33(12):1699-1708

45. Pantea D, Darmstadt H, Kaliaguine S, Roy C (2003) Electrical conductivity of conductive carbon blacks: influence of surface chemistry and topology. Appl Surf Sci 217(1-4):181-193

46. Sánchez-González J, Macías-García A, Alexandre-Franco MF, Gómez-Serrano V (2005) Electrical conductivity of carbon blacks under compression. Carbon 43(4):741-747

47. Carmona F, Ravier J (2002) Electrical properties and mesostructure of carbon black-filled polymers. Carbon 40(2):151-156

48. Demtchelis F, Pirri CF, Tresso E (1993) Degree of crystallinity and electrical transport properties of microcrystalline silicon-carbon alloys. Philosophical Magazine Part B 67(3):331-346

49. Probst N, Grivei E (2002) Structure and electrical properties of carbon black. Carbon 40(2):201-205

50. Dongil AB, Pastor-Pérez L, Fierro JLG, Escalona N, SepúlvedaEscribano A (2016) Effect of the surface oxidation of carbon nanotubes on the selective cyclization of citronellal. Appl Catal A 524:25-31

51. Garba A, Basri H, Nasri NS, Isma'il R (2006) Synthesis and characterization of porous carbon from biomass using $\mathrm{KOH}$ and $\mathrm{K}_{2} \mathrm{CO}_{3}$ chemical activation. ARPN J Eng Appl Sci 11(3):1613-1617

52. Stavropoulos GG, Samaras P, Sakellaropoulos GP (2008) Effect of activated carbons modification on porosity, surface structure and phenol adsorption. J Hazard Mater 151(2-3):414-421
53. Wang X, Gao Y, Wang J, Wang Z, Chen L (2015) Chemical adsorption: another way to anchor polysulfides. Nano Energy 12:810-815

54. Shaibani $M$, Akbari $A$, Sheath $P$, Easton $C D$, Banerjee PC, Konstas K, Fakhfouri A, Barghamadi M, Musameh MM, Best AS, Rüther T, Mahon PJ, Hill MR, Hollenkamp AF, Majumder M (2016) Suppressed polysulfide crossover in $\mathrm{Li}-\mathrm{S}$ batteries through a highflux graphene oxide membrane supported on a sulfur cathode. ACS Nano 10(8):7768-7779

55. Gu P-Y, Zhao Y, Xie J, Binte Ali N, Nie L, Xu ZJ, Zhang Q (2016) Improving the Performance of Lithium-Sulfur Batteries by Employing Polyimide Particles as Hosting Matrixes. ACS Appl Mater Interfaces 8(11):7464-7470

56. Xu Y, Wen Y, Zhu Y, Wang C, Gaskell K, Eichhorn B, Cychosz KA, Xu K (2015) Confined Sulfur in Microporous Carbon Renders Superior Cycling Stability in Li/S Batteries. Adv Func Mater 25(27):4312-4320

57. Gu S, Wen Z, Qian R, Jin J, Wang Q, Wu M, Zhuo S (2016) Carbon disulfide cosolvent electrolytes for high-performance lithium sulfur batteries. ACS Appl Mater Interfaces 8(50):34379-34386

58. Levi M, Aurbach D (2004) Impedance of a single intercalation particle and of non-homogeneous, multilayered porous composite electrodes for Li-ion batteries. J Phys Chem B 108(31):11693-11703

59. Zhang SS (2013) Does the sulfur cathode require good mixing for a liquid electrolyte lithium/sulfur cell? Electrochem Commun 31:10-12

60. Manthiram A, Fu Y, Su Y-S (2013) Challenges and Prospects of Lithium-Sulfur Batteries. Acc Chem Res 46(5):1125-1134

Publisher's Note Springer Nature remains neutral with regard to jurisdictional claims in published maps and institutional affiliations. 